\title{
A case of traumatic corneal stromal edema with decreased endothelial cell density
}

This article was published in the following Dove Press journal:

International Medical Case Reports Journal

26 June 2015

Number of times this article has been viewed

\author{
Jung-Hoon Kim \\ Sa Kang Kim \\ Sang Beom Han \\ Seung-Jun Lee \\ Moosang Kim
}

Department of Ophthalmology, School of Medicine, Kangwon National University, Chuncheon, Korea
Correspondence: Moosang Kim Department of Ophthalmology, School of Medicine, Kangwon National University,

I56 Baengnyeong-ro, Chuncheon,

Gangwon 200-722, Korea

Tel +823325820l4

Fax +82332582000

Email kimmoo-79@hanmail.net

\begin{abstract}
A 31-year-old man presented to our clinic for an ocular trauma to his left eye. His best-corrected visual acuity was 20/200 OS (left eye). Anterior segment examination showed an epithelial defect, which implies a direct injury to the cornea. A marked focal stromal edema accompanied by Descemet's membrane folds were located at 10 o'clock in the paraxial area, about $4 \mathrm{~mm}$ apart from the corneal center. Anterior segment optical coherence tomography (AS-OCT) revealed marked corneal swelling of the lesion. Five days later, the patient's best-corrected visual acuity improved to 20/50 OS. The stromal edema resolved showing no signs of epithelial defect, although small opacity remained. AS-OCT revealed complete resolution of corneal swelling. Despite the resolution of corneal edema, however, specular microscopy showed substantially decreased endothelial cell density in the lesion compared to the fellow eye. Here we report a case of traumatic corneal stromal edema discovered by AS-OCT.
\end{abstract}

Keywords: AS-OCT, stromal edema, trauma

\section{Introduction}

Ocular trauma, although relatively rare, is a proven etiology of focal corneal stromal edema. A notable example of corneal edema caused by trauma is traumatic corneal endothelial rings. Not many cases have been reported since it was described in 1978 by Cibis et al. ${ }^{1}$ Ocular manifestations include lesions of transient, gray-white, endothelial ring-shaped opacities with focal corneal stromal edema and most cases show remission within a few days with conservative management. ${ }^{2}$ Here we report a case of traumatic corneal stromal edema discovered by anterior segment optical coherence tomography (AS-OCT).

\section{Case report}

A 31-year-old man presented to our clinic for an ocular trauma to his left eye. The patient had a blast injury which occurred on the previous day by a plastic bottle cap when trying to open a beverage bottle. Past medical history was unremarkable. His best-corrected visual acuity (BCVA) was 20/200 OS (left eye). Anterior segment examination showed an epithelial defect, which implies a direct injury to the cornea. A marked focal stromal edema accompanied by Descemet's membrane folds were located at 10 o'clock in the paraxial area, about $4 \mathrm{~mm}$ apart from the corneal center (Figure 1A). Grade 1 gross hyphema was observed. AS-OCT (AS-OCT; Carl Zeiss Meditec AG, Jena, Germany) revealed marked corneal swelling of the lesion (Figure 1B). Endothelial cell density was 1783 cells $/ \mathrm{mm}^{2}$ (Figure 1C). Funduscopic examination showed clear vitreous with normal optic disc and retina. The patient was given topical cycloplegics and 1\% prednisolone 

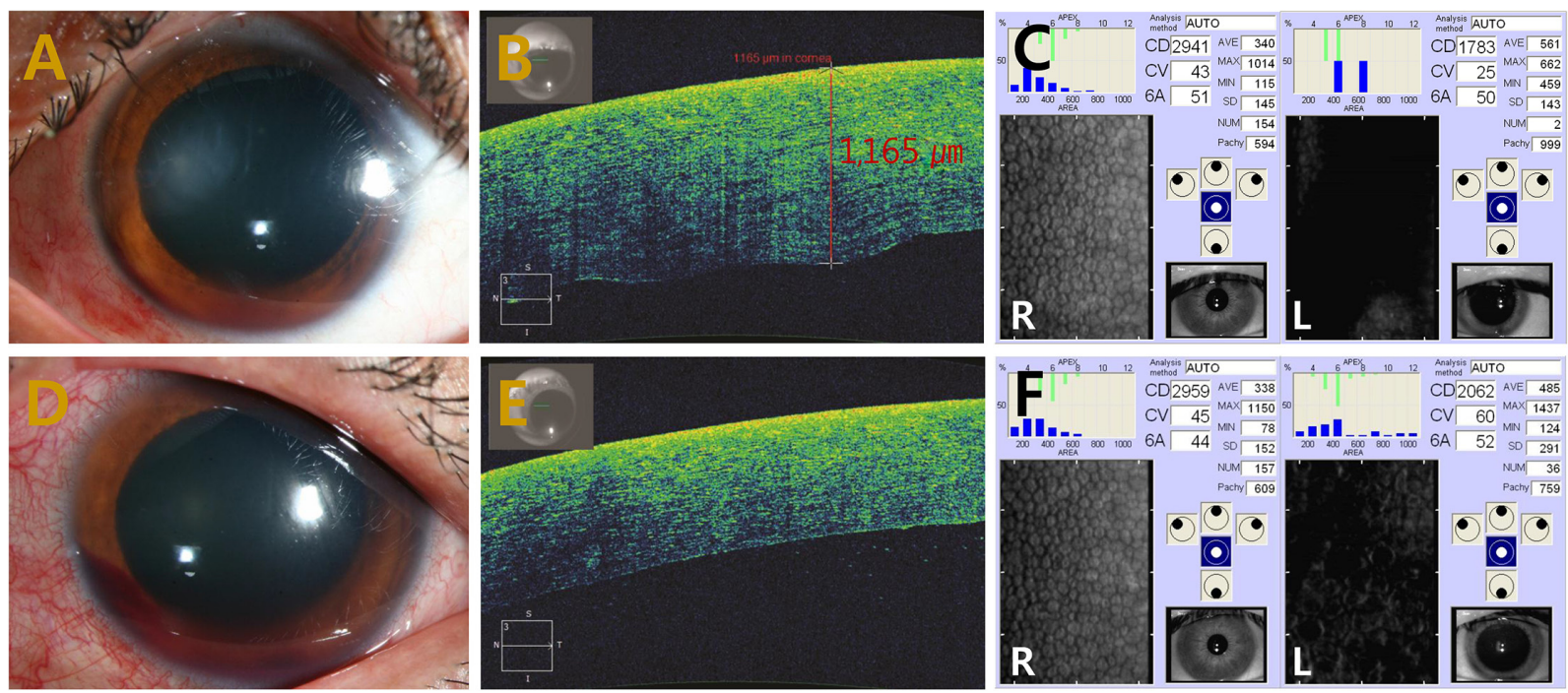

Figure I Marked focal corneal edema $\rightarrow$ marked focal stromal edema.

Notes: (A) Anterior segment photography showing a marked focal corneal edema. (B) Anterior segment optical coherence tomography demonstrating severe corneal swelling and markedly increased corneal thickness in the affected area. (C) Specular microscopy revealing decreased endothelial cell density and increased corneal thickness. (D) Anterior segment photography showing resolution of corneal edema through conservative management. (E) Anterior segment optical coherence tomography demonstrating complete resolution of corneal swelling. (F) Specular microscopy revealing substantially decreased endothelial cell density in the left $(\mathrm{L})$ eye compared to the right $(\mathrm{R})$ eye.

acetate every 2 hours. Five days later, his BCVA improved to 20/50 OS. The stromal edema resolved, showing no signs of epithelial defect, although small opacity remained (Figure 1D). AS-OCT revealed complete resolution of corneal swelling (Figure 1E). Despite the resolution of corneal edema, however, specular microscopy (SP-9000; Konan Medical, Tokyo, Japan) showed substantially decreased endothelial cell density in the lesion compared to the fellow eye $\left(2,062\right.$ versus $\left.2,959 \mathrm{~mm}^{2}\right)$ (Figure 1F). The patient's condition was observed while tapering the topical steroid. One month later, the patient's 2959 cells $/ \mathrm{mm}^{2}$ BCVA improved to 20/25 OS. There were no signs of corneal edema and no further decrease in endothelial cell density.

\section{Discussion}

A diffuse corneal edema and its recovery is often observed in patients with eye injury caused by ocular trauma. The main etiologies of transient diffuse stromal edema include posttraumatic inflammation inside the anterior chamber and persistently increased intraocular pressure. However, a local corneal edema accompanied by substantially decreased endothelial cell is a rare and notable case. This case differs from traumatic corneal endothelial rings in that there is no distinct endothelial ring lesion on slit lamp examination. Furthermore, despite the difference in corneal morphology, this case shares a similarity with the traumatic corneal endothelial rings: the corneal lesion was caused by traumatic endothelial cell damage in this case. To our knowledge, only one case of traumatic corneal endothelial rings with imaging of AS-OCT has been reported, ${ }^{3}$ in which the AS-OCT revealed a ruffled disruption to the endothelial cells directly posterior to the stromal thickening. We too discovered a similar ruffled endothelial disruption from imaging (Figure 1B). Endothelial cells around the traumatic lesion undergo the greatest torsion and energy absorption as the cornea moves axially posterior and then relaxes to its original position. ${ }^{4}$ This process could have induced the damage and inflammation of the corneal endothelial cells. Another possible mechanism that caused the injury would be a direct contact between the corneal endothelium and a lens or iris. Dysfunction of damaged endothelial cells are replaced with circumferential normal endothelial cells. The proper functioning of the corneal endothelium is regarded to be crucial to the maintenance of corneal clarity. Once damaged, the endothelium is not able to recover from the injury. Therefore, significant endothelial damage may lead to severe complications such as persistent corneal edema and bullous keratopathy at a later stage.

\section{Conclusion}

In conclusion, permanent corneal endothelial cell loss could occurs by traumatic mechanism, which manifests as corneal stromal edema in the early phase of trauma. Corneal endothelial layer evaluation using specular microscopy and AS-OCT can be useful for diagnosing and monitoring the damage to cornea.

\section{Disclosure}

The authors report no conflicts of interest in this work. 


\section{References}

1. Cibis GW, Weingeist TA, Krachmer JH. Traumatic corneal endothelial rings. Arch Ophthalmol. 1978;96(3):485-488.

2. Ng SK, Rudkin AK, Galanopoulos A. Traumatic corneal endothelial rings from homemade explosives. Int Ophthalmol. 2013;33(4):395-397.
3. Reid GA, Musa F. OCT Imaging of a Traumatic Endothelial Ring. Cornea. 2014;33(9):952-954.

4. Maloney WF, Colvard M, Bourne WM, Gardon R. Specular microscopy of traumatic posterior annular keratopathy. Arch Ophthalmol. 1979;97(9):1647-1650

\section{Publish your work in this journal}

The International Medical Case Reports Journal is an international, peer-reviewed open-access journal publishing original case reports from all medical specialties. Previously unpublished medical posters are also accepted relating to any area of clinical or preclinical science. Submissions should not normally exceed 2,000 words or
4 published pages including figures, diagrams and references. The manuscript management system is completely online and includes a very quick and fair peer-review system, which is all easy to use. Visit http://www.dovepress.com/testimonials.php to read real quotes from published authors.

Submit your manuscript here: http://www.dovepress.com/international-medical-case-reports-journal-journal 